\title{
Multi-dimensional Evaluation Model of E-commerce Industrial Chain
}

\author{
Hu Tao Zhuang Xinghua* and Liu Kun
}

\author{
School of Economics and Management. Beijing University of Posts and Telecommunications, 100876, China
}

\begin{abstract}
As for the serious impediment of credit to the rapid development of e-commerce cooperative management, this paper proposes the multi-dimensional evaluation model of the cooperative management of e-commerce based on credit, from the dimensions of the identification of the mechanism of the e-commerce industrial chain, the comprehensive strength of enterprise, enterprise credit score, etc. For different dimensions, this paper puts forward a reasonable calculation method, strives to implement differentiated management for different companies and gives some suggestions on rewards and punishments.
\end{abstract}

Keywords: E-commerce industrial chain, credit, multi-dimensional evaluation model, hierarchical management.

\section{THE PREFACE}

According to "The report of 2013 Annual e-commerce market data monitoring in China," at the end of 2013 the amount of e-commerce transactions reached 10.2 trillion, and it is expected that by the end of 2014 the amount will reach 13.4 trillion. With the increasing influence of e-commerce on the economy in China, the concept of 'the cooperation of industrial chain' centering on the e-commerce platform begins to emerge. The industrial chain of e-commerce runs through product manufacturing, supply, sales, warehousing, logistics, payments, users, etc, the purpose of which is to seek collaboration between all sectors of such a chain, and ultimately maximize the overall profit of the industrial chain. For example, Amazon and its content providers EPIX, ESPN have reached an agreement on the enrichment of Amazon video content; Alibaba has signed an agreement with the Courier of some province, and the two sides would cooperate in logistics, warehousing and distribution in order to provide international express logistics service for the customers of AliExpress afflicted to Alibaba... As for the current situation, e-commerce platforms have launched corresponding policies to strengthen cooperation with the industry chain-related enterprises, in order to accelerate the pace of improvement on the structure of industry chain. However, there are still some problems with the current co-management of ecommerce industry, such as the irrationality of industry chain structure, the unscientific chain management, the lack of chain credit, the unreasonable regulatory mechanisms of e-commerce industry.

\section{THE OVERVIEW OF COOPERATIVE MANAGE- MENT OF E-COMMERCE INDUSTRIAL CHAIN}

There are many links in e-commerce industrial chain and can be divided into "e-Chain" and "business chain."
"E-Chain" includes infrastructure, platform software, application development, system integration, network equipment, terminal equipment, network communications, and its equipment; "Business Chain" includes goods available, distribution channels, market, financial services, media information, storage, packaging and transportation, logistics and distribution. The co-management of e-commerce industrial chain refers to the collaboration of product manufacturing, supply, sales, warehousing, logistics, payments, and users of the chain.

Choi, JH, Park, JS, Lee, JH, Ryu, KS (2006) [1] using the Balanced Scorecard card and the analysis method of value chain, have analyzed the key factors of e-commerce success - tangible assets, intangible assets, process composition; based on the analysis of the key elements of enterprise core competitiveness, they have provided recommendations for ecommerce industry to gain a competitive advantage: for example, the industry chain cooperation, asset restructuring and process optimization. Ma Xujun, Zong Gang (2011) [2] from a social rather than economic perspective, have built up the model of psychological contract for virtual enterprise to help companies recognize the meaning and importance of the psychological contract, while increasing the level of cooperation and satisfaction among members of virtual enterprise. Xiong Li (2011) [3] has pointed out that the maturity of ecommerce industrial chain would drive the development of e-commerce industrial clusters, and from the perspective of the network structure, has proposed the innovative model of vertical and horizontal networks of e-commerce industrial clusters. Chunhua Ju, Bin SUN, Dongsheng LIU (2012) [4], based on the analysis of the characteristics of suppliers, historical performance, cooperative ability, supply capacity and other factors, have built a mixed integer model for ecommerce alliance in certain sectors to select suppliers. Liu Ying and others (2012) [5] through game analysis have concluded that the upstream and downstream cooperation and innovation of the industrial chain is a win-win strategy, and using the Rubinstein bargaining model to determine the distribution of innovative cost-sharing and the remaining profits. 


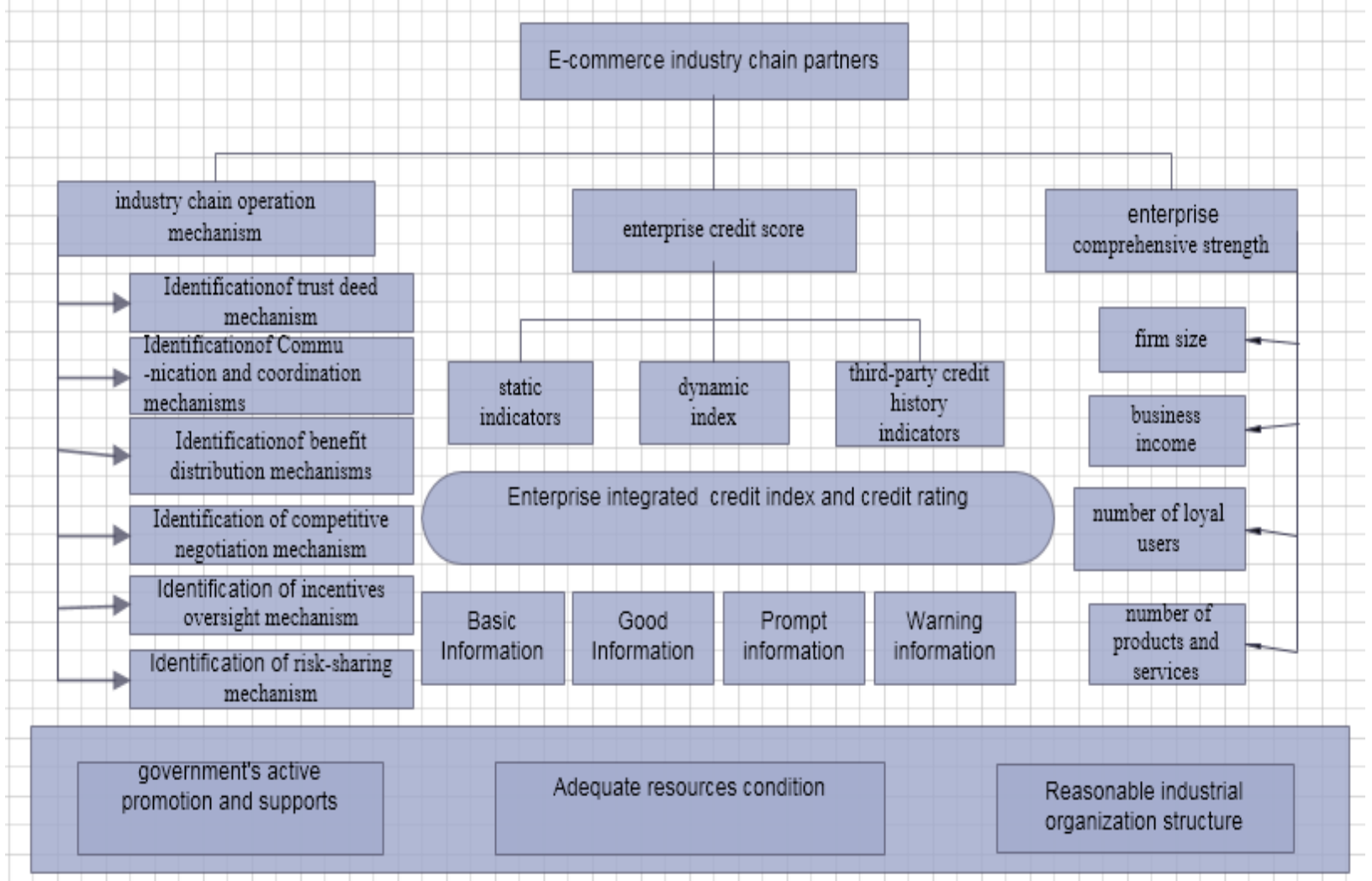

Fig. (1). The Hierarchical Evaluation Model of E-commerce Cooperative Management Based on Credit.

The above study is basically about the cooperation and win-win business strategy in e-commerce industrial chain. However, there is little study about how to better manage cooperative enterprises in e-commerce industrial chain, and still little research about their credit problems. To address this problem, this paper, based on the solution to the credit of cooperative management in e-commerce industrial chain, provides some support for the healthy and rapid development of e-commerce industry.

\section{THE ESTABLISHMENT OF E-COMMERCE CO- OPERATIVE MANAGEMENT MODEL}

Based on foregoing research, this paper has established ecommerce cooperative management model on credit and introduced the basic algorithm of the model.

\subsection{The Establishment of the Model}

This model is mainly used for the evaluation of the cooperative partners by e-commerce platforms. The main dimensions of the model selected internal factors affecting the competitiveness of the e-commerce industry chain, including the recognition of joint venture for the industry chain mechanism, the comprehensive strength of enterprise, integrating corporate credit and external factors such as the role of government, resources, the basis for industrial organization structure, bearing internal factors. In this way this paper established a model shown in Fig. (1).

The Identification of the mechanism of e-commerce industrial chain by cooperative enterprise can be considered from six indicators: identification of trust deed mechanism, identification of communication and coordination mechanisms, Identification of benefit distribution mechanisms, Identification of competitive negotiation mechanism, identification of incentives oversight mechanism, identification of risk-sharing mechanism; the comprehensive strength of enterprise can be considered from four indicators: firm size, the number of loyal users, the number of products and services, business income; corporation credit score can be considered from three indicators: static indicators, dynamic index, thirdparty credit history indicators. The results of the credit will be disclosed inside and outside of the enterprise, including the basic information, product information, tips information, warning information, and this paper will give companies a comprehensive credit index and credit rating.

\subsection{The Algorithm of Model}

Based on the three dimensions of evaluation of cooperative management in e-commerce industrial chain, this paper would make use of fuzzy comprehensive evaluation, differential transformation method, weighted sum method multidimensional to analyze specific issues.

\subsubsection{The Calculation of Identification of the Mechanism of the E-commerce Industrial Chain by Cooperative Enter- prise}

Let $A_{i}\left(a_{1}, a_{2}, a_{3}\right)$ be the composite score of the enterprise, $A_{i}\left(a_{1}, a_{2}, a_{3}\right)$ the score of degree of operating rapport between enterprises and the mechanism of e-commerce in- 
dustrial chain, the score of corporate comprehensive strength, corporate credit score.

Because of the fuzzy index of Identification of mechanism of the e-commerce industrial chain by joint venture, this paper would make use of fuzzy comprehensive evaluation method. The basic steps are as follows:

1. Determining the set of evaluation factors. Evaluation factors set is a collection of all the factors that affect the evaluation of an object, written as: $F=\left(F_{1}, F_{2}, \ldots, F_{m}\right)$. In this paper, the evaluation index for $a_{1}$ as shown in Table 2 (to be intuitive and easy, replace $a_{1}$ with F):

2. Determining the set of rating scale Evaluation scale set is a collection of various evaluation conclusions that evaluators make on evaluation object, written as: $V=\left(V_{1}, V_{2}, \ldots, V_{m}\right)$. Here rating scale is divided into five, namely, $\mathrm{V}=$ (excellent, good, fair, poor, very poor), expressed as a mathematical quantification $V=(2,1,0,-1,-2)$.

3. Determining the weight set of evaluation factors

Because the influence of various factors on the evaluation object is inconsistent, it is necessary to determine the weight factor $\alpha$, consisting of the weight set. Weight reallocation of evaluation factors are usually judged by a group of expert grasping the full information and being open broadly to the views, and weight distribution set is a fuzzy set based on F. Generally be written as: $\alpha=\left(\alpha_{1}, \alpha_{2}, \ldots, \alpha_{m}\right)$, in which $a_{i}$ denotes the weight of $i-\operatorname{th}(i=1,2, \cdots, m)=1,2, m)$, meeting the needs of the normalization condition, namely $\sum_{i=1}^{m} \alpha_{i}$.

4, The first level of fuzzy evaluation

Make fuzzy evaluation on univariate set and establish a fuzzy evaluation matrix $R\left(R_{i j}\right)$. Univariate fuzzy evaluation subset: $R_{i}=\left(R_{i 1}, R_{i 2}, \ldots, R_{i n}\right)$, which means each value evaluated on each object at different levels of quality, for each evaluation index i. Fuzzy evaluation matrix $\mathrm{R}$ is as follows:

$$
R=\left[\begin{array}{cccc}
R_{11} & R_{12} & \cdots & R_{1 n} \\
R_{21} & R_{22} & \cdots & R_{2 n} \\
\vdots & \vdots & \ddots & \vdots \\
R_{m 1} & R_{m 2} & \cdots & R_{m n}
\end{array}\right]
$$

5、 The second level of fuzzy comprehensive evaluation

Using fuzzy composite operator $\mathrm{M}(0,+)$, the data is processed to generate fuzzy evaluation vector

$$
B: B=\alpha \cdot R=\left(a_{1}, a_{2}, \cdots, a_{m}\right) \bullet\left[\begin{array}{cccc}
R_{11} & R_{12} & \cdots & R_{1 n} \\
R_{21} & R_{22} & \cdots & R_{2 n} \\
\vdots & \vdots & \ddots & \vdots \\
R_{m 1} & R_{m 2} & \cdots & R_{m m}
\end{array}\right]
$$

$=\left(b_{1}, b_{2}, \cdots, b_{n}\right)$
Here, $b_{j}$ denotes the degree of membership of the object belonging to fuzzy subset. Multi-level fuzzy evaluation can be understood as the comprehension of a little single-level fuzzy evaluation. For example, Table $\mathbf{2}$ and Table $\mathbf{1}$ corresponde, wherein $\alpha_{i}$ represents the weight of factor $\mathrm{F}_{\mathrm{i}}, \alpha_{i j}$ represents the weight of $F_{i j}, V_{n}$ represents the rating scale $R_{i j n}$, the degree of association between Fij and Vn, and the weight set of evaluation results given by the expert group. Firstly determine the membership of the secondary evaluation index to evaluation set $\mathrm{V}$, as shown in Table 2 . Then establish the evaluation matrix of secondary indicators, and finally make a comprehensive evaluation:

$R_{1}=\left[\begin{array}{lllll}R_{111} & R_{112} & R_{113} & R_{114} & R_{115} \\ R_{121} & R_{122} & R_{123} & R_{124} & R_{125} \\ R_{131} & R_{132} & R_{133} & R_{134} & R_{135} \\ R_{141} & R_{142} & R_{143} & R_{144} & R_{145} \\ R_{151} & R_{152} & R_{153} & R_{154} & R_{155}\end{array}\right]$

$B_{1}=\alpha_{1} \cdot R_{1}=\left(\alpha_{11}, \alpha_{12}, \alpha_{13}, \alpha_{14}, \alpha_{15}\right)=$

$\left[\begin{array}{lllll}R_{111} & R_{112} & R_{113} & R_{114} & R_{115} \\ R_{121} & R_{122} & R_{123} & R_{124} & R_{125} \\ R_{131} & R_{132} & R_{133} & R_{134} & R_{135} \\ R_{141} & R_{142} & R_{143} & R_{144} & R_{145} \\ R_{151} & R_{152} & R_{153} & R_{154} & R_{155}\end{array}\right]=\left(b_{11}, b_{12}, b_{13}, b_{14}, b_{15}\right)$

Similarly,

$B_{2}=\left(b_{21}, b_{22}, b_{23}, b_{24}, b_{25}\right) \quad, \quad B_{3}=\left(b_{31}, b_{32}, b_{33}, b_{34}, b_{35}\right)$,

$B_{4}=\left(b_{41}, b_{42}, b_{43}, b_{44}, b_{45}\right) \quad, \quad B_{5}=\left(b_{51}, b_{52}, b_{53}, b_{54}, b_{55}\right)$,

$B_{6}=\left(b_{61}, b_{62}, b_{63}, b_{64}, b_{65}\right)$

Then goes the normalization, namely: $b^{\prime}{ }_{i k}=b_{i k} / \sum_{k=1}^{5} b_{i k}$

So,

$B_{1}^{\prime}=\left(b_{11}^{\prime}, b_{12}^{\prime}, b_{13}^{\prime}, b_{14}^{\prime}, b_{15}^{\prime}\right), B_{2}^{\prime}=\left(b_{21}^{\prime}, b_{22}^{\prime}, b_{23}^{\prime}, b_{24}^{\prime}, b_{25}^{\prime}\right)$, $B^{\prime}{ }_{3}=\left(b^{\prime}{ }_{31}, b^{\prime}{ }_{32}, b_{33}^{\prime}, b^{\prime}{ }_{34}, b^{\prime}{ }_{35}\right), B^{\prime}{ }_{4}=\left(b^{\prime}{ }_{41}, b_{42}^{\prime}, b_{43}^{\prime}, b_{44}^{\prime}, b^{\prime}{ }_{45}\right)$, $B^{\prime}{ }_{5}=\left(b^{\prime}{ }_{51}, b^{\prime}{ }_{52}, b^{\prime}{ }_{53}, b^{\prime}{ }_{54}, b^{\prime}{ }_{55}\right), B^{\prime}{ }_{6}=\left(b^{\prime}{ }_{61}, b^{\prime}{ }_{62}, b^{\prime}{ }_{63}, b^{\prime}{ }_{64}, b_{65}^{\prime}\right)$

The paper uses results normalized as an evaluation transformation matrix of first-stage index,

$$
R=\left[\begin{array}{lllll}
b_{11}^{\prime} & b_{12}^{\prime} & b_{13}^{\prime} & b_{14}^{\prime} & b_{15}^{\prime} \\
b_{21}^{\prime} & b_{22}^{\prime} & b_{23}^{\prime} & b_{24}^{\prime} & b_{25}^{\prime} \\
b_{31}^{\prime} & b_{32}^{\prime} & b_{33}^{\prime} & b_{34}^{\prime} & b_{35}^{\prime} \\
b_{41}^{\prime} & b_{42}^{\prime} & b_{43}^{\prime} & b_{44}^{\prime} & b^{\prime} \\
b_{51}^{\prime} & b_{52}^{\prime} & b_{53}^{\prime} & b_{54}^{\prime} & b_{55}^{\prime} \\
b_{61}^{\prime} & b_{62}^{\prime} & b_{63}^{\prime} & b_{64}^{\prime} & b^{\prime}
\end{array}\right]
$$


Table 1. Evaluation Factors Set.

The Identification of e-commerce industry chain mechanism by cooperative enterprise $\mathrm{F}$

\begin{tabular}{|c|c|}
\hline \multirow{5}{*}{ Identification of trust deed mechanism $\mathrm{F}_{1}$} & Mutual understanding $\mathrm{F}_{11}$ \\
\hline & Communication $_{12}$ \\
\hline & Fair cooperation $F_{13}$ \\
\hline & Learning from each otherF $F_{14}$ \\
\hline & Honest and trustworthy $F_{15}$ \\
\hline \multirow{3}{*}{$\begin{array}{l}\text { Identification of communication and coordination mech- } \\
\qquad \text { anisms } F_{2}\end{array}$} & AlignmentF $\mathrm{F}_{21}$ \\
\hline & Mutual trust $F_{22}$ \\
\hline & Communication and consultationF $\mathrm{F}_{23}$ \\
\hline \multirow{4}{*}{ Identification of benefit distribution mechanisms $\mathrm{F}_{3}$} & Reasonable allocation of the remaining profit $\mathrm{F}_{31}$ \\
\hline & Symmetry of pay and benefits $F_{32}$ \\
\hline & Symmetry of risks and benefits $\mathrm{F}_{33}$ \\
\hline & Comprehensive Optimization $\mathrm{F}_{34}$ \\
\hline \multirow{3}{*}{ Identification of competitive negotiation mechanism $\mathrm{F}_{4}$} & Win-win solution $\mathrm{F}_{41}$ \\
\hline & Maximizing the value of objective $\mathrm{F}_{42}$ \\
\hline & Accordance with the law $\mathrm{F}_{43}$ \\
\hline \multirow{5}{*}{ Identification of incentives oversight mechanism $\mathrm{F}_{5}$} & Price incentive $\mathrm{F}_{51}$ \\
\hline & Order Incentive $\mathrm{F}_{52}$ \\
\hline & Goodwill incentive $\mathrm{F}_{53}$ \\
\hline & Eliminate incentive $\mathrm{F}_{54}$ \\
\hline & Information incentive $\mathrm{F}_{55}$ \\
\hline \multirow{2}{*}{ Identification of risk-sharing mechanism $\mathrm{F}_{6}$} & Spread risk of management $\mathrm{F}_{61}$ \\
\hline & Symmetry of risk and profitability $\mathrm{F}_{62}$ \\
\hline
\end{tabular}

Table 2. Rating Scale and Evaluation Ratio.

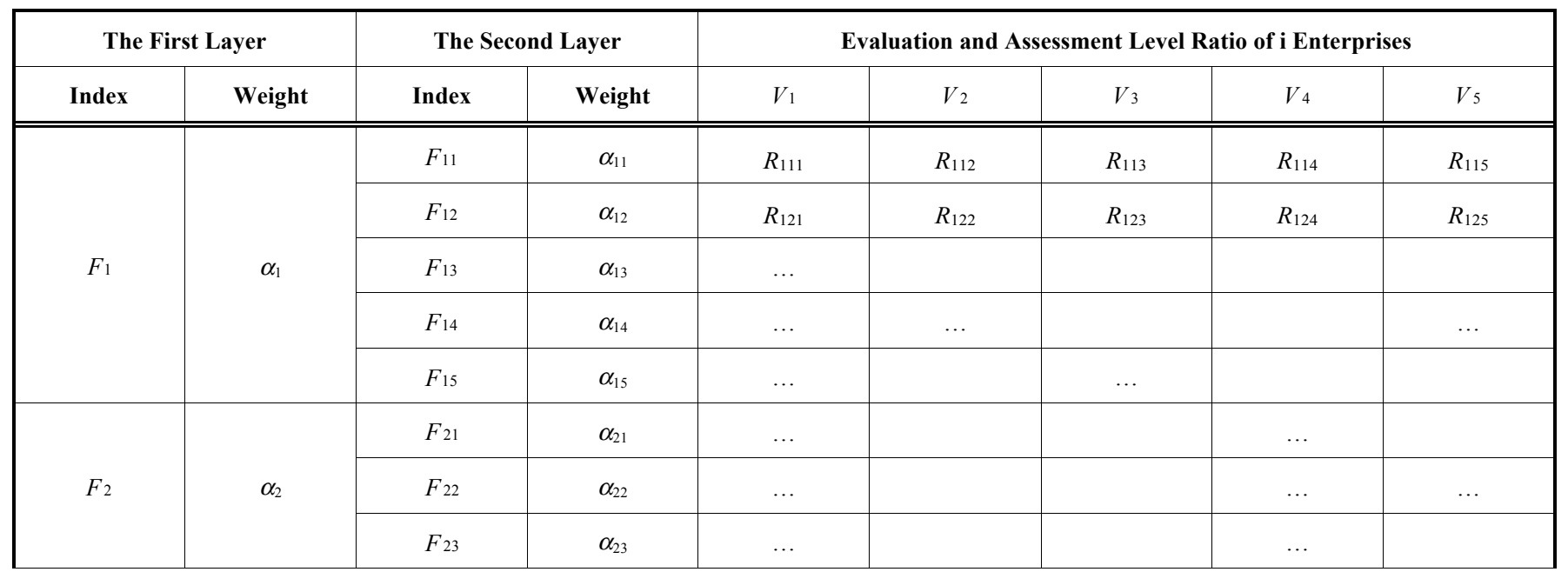


Table 2. contd...

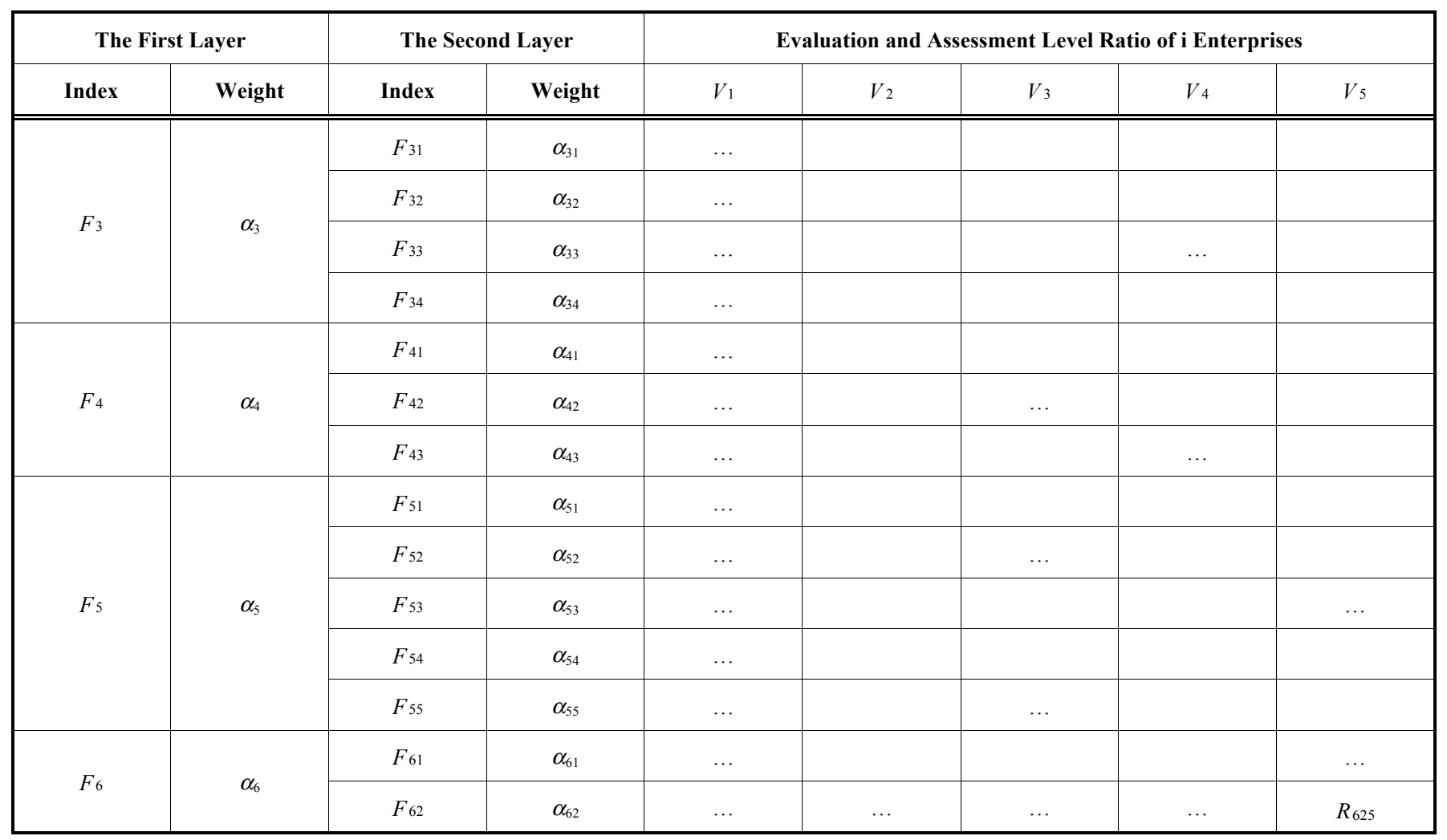

$B=\alpha \cdot R=\left(\alpha_{1}, \alpha_{2}, \cdots, \alpha_{6}\right) \bullet$

$\left[\begin{array}{lllll}b_{11}^{\prime} & b_{12}^{\prime} & b_{13}^{\prime} & b_{14}^{\prime} & b_{15}^{\prime} \\ b_{21}^{\prime} & b_{22}^{\prime} & b_{23}^{\prime} & b_{24}^{\prime} & b_{25}^{\prime} \\ b_{31}^{\prime} & b_{32}^{\prime} & b_{33}^{\prime} & b_{34}^{\prime} & b_{35}^{\prime} \\ b_{41}^{\prime} & b^{\prime}{ }_{42}^{\prime} & b_{43}^{\prime} & b_{44}^{\prime} & b_{45}^{\prime} \\ b_{51}^{\prime} & b_{52}^{\prime} & b_{53}^{\prime} & b_{54}^{\prime} & b_{55}^{\prime} \\ b_{61}^{\prime} & b_{62}^{\prime} & b_{63}^{\prime} & b_{64}^{\prime} & b_{65}^{\prime}\end{array}\right]=$

$\left(b_{1}, b_{2}, b_{3}, b_{4}, b_{5}\right)$

Here goes the normalization, then $B^{\prime}=\left(b_{1}^{\prime}, b_{2}^{\prime}, b_{3}^{\prime}, b_{4}^{\prime}, b_{5}^{\prime}\right)$.

Quantify each grade in evaluation set and get the results: $\mathrm{V}=(2,1,0,-1,-2)$, then make a comprehensive evaluation on harmonious degree of $\mathrm{i}$ business and mechanism of e-commerce industrial chain: $B_{v}=B^{\prime} \cdot V^{T}$, that $a_{1}=B_{v}=$ $B^{\prime} \cdot V^{T}$.

\subsubsection{The Integral Algorithm Of Enterprise Credit}

For business credit scorea 3, there are three dimensions: static index, dynamic index, and the third-party credit record. According to the characteristics of each dimension, a_3 can be divided into static and dynamic integration, in which static integration includes static integral indicators and thirdparty credit history score, while dynamic integration includes dynamic index score.

1 , If $\mathrm{S}$ refers to the static initial integration of the cooperative enterprises in e-commerce industrial chain, $C(i)$ and $D(i)$ irefer to the static factors and the existing credit history of the corporation, then we have:

$$
S(f)=\sum C(i)+\sum D(i)
$$

where according to the situation of static indicators, $C(i)$ can be divided into several levels, and determine the scores for each grade; $D(i)$ indicates the existing credit history scores: positive record is positive score, bad credit is negative scores, the standard of which is determined by the core enterprise in the industrial chain. For example, the value of $D(i)$ of 5A-class companies are 100 points, 4A-class companies 80 points, $3 \mathrm{~A}$ class enterprise 60 points, $2 \mathrm{~A}$ class enterprise 40 points, A-level enterprises 20 points [6].

2, $\mathrm{T}$ represents the dynamic integration of cooperative enterprise in e-commerce industrial chain and includes four indicators: transaction status, production quality, information quality, user evaluation, and can be calculated from two dimensions, that is, the type of business and trading. Weights set are represented in Table 3 .

If $K_{j}$ refers as the weight of the indicator $E_{j}$ corresponding dimension $F_{i}$, then as for the single dimen$\operatorname{sion} F_{i}$ we have: 
Table 3. The Set of Weights of Dynamic Integration.

\begin{tabular}{|c|c|c|c|}
\hline \multirow{2}{*}{\multicolumn{2}{|c|}{ Dimension Indicator }} & $\begin{array}{c}\text { Business Type } \\
U_{1}\end{array}$ & $\begin{array}{c}\text { Trading Type } \\
U_{2}\end{array}$ \\
\hline & & Weight $\alpha$ & Weight $\delta$ \\
\hline \multirow{3}{*}{ Transaction status $E_{1}$} & sales $E_{11}$ & $K_{11}$ & $K_{11}$ \\
\hline & The growth rate of sales $E_{12}$ & $K_{12}$ & $K_{12}$ \\
\hline & The amount of transaction $E_{13}$ & $K_{13}$ & $K_{13}$ \\
\hline \multicolumn{2}{|c|}{ Production quality $E_{2}$} & $K_{2}$ & $K_{2}$ \\
\hline \multicolumn{2}{|c|}{ Information quality $E_{3}$} & $K_{3}$ & $K_{3}$ \\
\hline \multicolumn{2}{|c|}{ User evaluation $E_{4}$} & $K_{4}$ & $K_{4}$ \\
\hline
\end{tabular}

$T\left(F_{i}\right)(u)=\sum_{j=1}^{2} K_{j} E_{j}\left(U_{i}\right)$

Where the calculation of $E_{1}\left(U_{i}\right)$ has two grades, the second can be calculated by referring to the indicator $K_{1 j}$ as the weight of $E_{1 j}$ corresponding dimension $U_{i}$, then we have $E_{1}\left(F_{i}\right)=\sum_{j=1}^{2} K_{1 j} E_{1 j}\left(U_{i}\right) \quad$ And we have $a_{3}=S(u)+\sum T\left(U_{i}\right)(u)=\sum C(i)+\sum D(i)+T\left(U_{1}\right) \bullet \alpha+T\left(U_{2}\right) \bullet \beta$.

To ensure that $a_{1}, a_{2}, a_{3}$ have the same order of magnitude, and facilitate a comprehensive description, it's necessary to normalize $a_{3}$ with min $a_{3}$ indicating in the current year (year $\mathrm{j}$ ) the smallest $a_{3}$ value of all similar enterprises, max $a_{3}$ indicating the largest $a_{3}$ value of all similar enterprises. Then we have: $a_{3}=\left(a_{3}^{\prime}-\min a_{3 j}^{\prime}\right) /\left(\max a_{3}^{\prime}-\min a_{3 j}^{\prime}\right)$

\subsubsection{The Calculation Method of Comprehensive Strength}

The integration of comprehensive strength is composed of this year (year $\mathrm{j}$ ) enterprise scale $A_{1 j}$, the number of loyal users $A_{2 j}$, the number of products and services $A_{3 j}$, business income $A_{4 j}$, and set their weights: $m_{1}{ }^{\prime} m_{2}, m_{3}, m_{4}$ and. $\sum_{k=1}^{4} m_{k}=1 a$.Through differential conversion and weighted sum of the indicators, this paper can get the integration of the enterprise comprehensive strength:

Let the evaluation index of enterprise comprehensive strength scale $A_{1 j}$ be $Q\left(A_{1 j}\right)$, then we have the equation below which can be obtained using differential transformation method:

$$
Q\left(A_{1 j}\right)=\left(A_{1 j}-\min A_{j}\right) /\left(\max A_{j}-\min A_{j}\right)
$$

In which, min $A_{j}$ is this year (year $\mathrm{j}$ ) the smallest value of enterprise scale similar enterprises, $\max A_{j}$ is this year (year j) the largest value of enterprise-scale in similar enterprises. $Q\left(A_{1 j}\right)$ between 0 and 1 , and one of the best, 0 is the worst value. Similarly, let comprehensive strength evaluation index of loyal users $A_{2 j}$ be $Q\left(A_{2 j}\right)$, the overall strength evaluation index of the number of product and service $A_{3 j}$ be $Q\left(A_{3 j}\right)$ the overall strength evaluation index of the business income $A_{4 j}$ be $Q\left(A_{4 j}\right)$, then the score of enterprise comprehensive strength cooperating with each other in e-commerce industrial chain was $a_{2}=\sum_{k=1}^{4} Q\left(A_{k j}\right) m_{k} \cdot$

\section{HIERARCHICAL MANAGEMENT OF PARTNERS IN E-COMMERCE INDUSTRIAL CHAIN}

This section will focus on the three dimensions of partners in e-commerce industrial chain to analyze and according to the corresponding results, to give appropriate preferential policies given in the channel, source, price, activities, etc. The purpose is to encourage the enterprises to increase their credit transactions for the rapid development of e-commerce industry chain to contribute.

\subsection{The Management Approach to the Degree of Identi- fication by Cooperative Enterprise in the E-commerce Industrial Chain}

According to the fuzzy comprehensive evaluation method, we can calculate the weights. Considering the time available, each indicator can be judged every six months or every three months. According to the weight of each index corresponding to the system, we can understand the degree of business performance in the above six identifications. So we can adopt differentiated management strategy to different enterprises. 
For example, in the case that there is no significant difference in the other five degrees of identification, and that there is a clear difference in the mechanism, then high-trust corporate can get more opportunities to cooperate with other companies with similar degrees of identification and can also get support from e-commerce platforms in resources, technology, and talent support. To those companies with low degrees of identification, we should first give them a warning in order to improve these companies in mutual understanding, fair cooperation, complementation, honesty and trust. If they fail again and again, and then adopt the elimination mechanism in order to make some bad- credit companies gradually disappear in the e-commerce platforms.

\subsection{The Management Approach To Corporate Credit Score}

Corporate credit score will be considered in three aspects, that is, static index, dynamic index, and the indicators of third-party credit history. According to the record in the rating period, implement the appropriate promotion and incentive policies, such as reducing the number of assessment, green channel of business process, priority service, and discounts of fees, cooperation support which has many aspects such as resources support, technical support, human resources support, etc. To those who have poor performance in the cycle of business rating, first we give them a warning; if next time they still have not improved, then adopt the demotion strategy and reduce the corresponding support, and put them on record.

\subsection{The Management Approach to Comprehensive Strength of Enterprise}

The comprehensive strength of enterprise consists of firm size, the number of loyal users, the number of products and services. By means of differential transformation method to calculate the above assessment of the comprehensive strength of the respective company, we can understand the current state of the business. According to the assessment results e-commerce platforms can implement appropriate management strategies. For example, we can rate the comprehensive strength of enterprise every three months. If it's proved that companies with high ratings have strong comprehensive strength, then we can give them long-term cooperation, as well as a very high-level service and support. For the company with low rating, we will take it out of the system after the first warning, so that the degree of trust between partners increases.

\subsection{The Integrated Management Approach to Partners in E-commerce Industrial Chain}

Considering the above three management approaches, and such three dimensions as the degree of identification of e-commerce industrial chain by cooperative enterprises, their comprehensive strength, and enterprise credit score, we can obtain the overall evaluation of partners in e-commerce industrial chain. According to the corresponding algorithm, we can divide the appropriate grades by which we can determine different types of incentive mechanisms.

For example, to those companies with continuous high credit ratings in the rating period, we should implement long-term strategic cooperation, plus mechanism, easy cooperation permissions (priority of service circle, discounts of fees), cooperative support (resources support, technical support, human resources support, etc.); to those with low grades, we should implement elimination mechanism, giving a warning before the elimination, so as to fully encourage enterprises to credit transactions.

\section{SUMMARY}

From the perspective of e-commerce industrial chain, collaborative management becomes a hot research topic. All e-commerce enterprises are aware that strengthening cooperative management in the chain, cooperation and win-win, is the effective way to break the status quo and seek higher development.

This paper carries out the research about the credit rating model of e-commerce co-management in three dimensions including the identification of the mechanism of e-commerce industrial chain, the comprehensive strength of the enterprise and corporate credit. According to the characteristics of the data, this paper has adopted the method of fuzzy comprehensive evaluation, differential transformation method and accurate multi-dimensional weighted sum method to calculate the assessed value, so as to ensure the objectivity, scientificity and accuracy of the scores to the greatest extent.

\section{ABOUT THE AUTHORS}

$\mathrm{Hu}$ Tao, Beijing, June 1966, Beijing University of Posts and Telecommunications, education background : 20032011, Doctor degree, graduating from Beijing university of posts and telecommunications; research field: the electronic commerce and network economy, Telecom value-added business, Information Management and Information System, Doctor degree.

Zhuang Xinghua, graduate, majoring in information management and information system Liu Kun, graduate, majoring in Information Management and Information System.

\section{CONFLICT OF INTEREST}

The author confirms that this article content has no conflict of interest.

\section{ACKNOWLEDGEMENTS}

Thanks to teacher of Hua Ying, Zhang XiaoHang and Wang Qi that they point out some of the valuable comments. I also thank to teacher of Lv TingJie for the model with some modifications made. Thanks Beijing University of Posts and Telecommunications that is able to provide such a good research environment. 


\section{REFERENCES}

[1] J.K. Choi, J.S. Park, Lee, and K.S. Ryu, "Key factors for ecommerce business success", Information Management, vol. 8, pp. 9-11, 2006.

[2] Ma X.Z. Gang, "Study of the cooperation between virtual enterprises from the perspective of psychological contract", IEEE, vol. 5, pp. 1-3, 2011.

[3] X. Li, "Research on the innovation of e-commerce industrial clusters in china based on the perspective of network structure", Information Management, vol.11, pp. 304-307, 2011.
[4] J.U. Chunhua, B. Sun, and D. Liu, "The research on the selection of suppliers for E-Commerce alliance”, SPIE, vol. 7490, 74902L174902L6, 2012.

[5] L. Zhiying, and L. Qinqin, "The analysis of vertical cooperative innovation alliance game model in firms of industry Chain", Science of Science and Management of $S \& T$, vol. 33, no. 6, pp. 3641, 2012.

[6] H. Tao, and H. Ying, "A dynamic multi-dimensional evaluation model applying to sp classification management", Journal of Beijing University of Posts and Telecommunication, vol.33, no.2, pp. 34-38, 2010.

Received: September 22, 2014

Revised: November 03, 2014

Accepted: November 06, 2014

(C) Xinghua and Kun; Licensee Bentham Open.

This is an open access article licensed under the terms of the Creative Commons Attribution Non-Commercial License (http://creativecommons.org/licenses/by-nc/3.0/) which permits unrestricted, non-commercial use, distribution and reproduction in any medium, provided the work is properly cited. 